\title{
A Systematic Assessment of Prevalence, Incidence and Regional Distribution of Multiple Sclerosis in Bavaria From 2006 to 2015
}

\begin{abstract}
Tanja Daltrozzo ${ }^{1 \dagger}$, Alexander Hapfelmeier ${ }^{2 \dagger}$, Ewan Donnachie ${ }^{3}$, Antonius Schneider ${ }^{4}$ and Bernhard Hemmer ${ }^{1,5 *}$

${ }^{1}$ Department of Neurology, Klinikum Rechts der Isar, School of Medicine, Technical University of Munich, Munich, Germany, ${ }^{2}$ School of Medicine, Institute of Medical Informatics, Statistics and Epidemiology, Technical University of Munich, Munich, Germany, ${ }^{3}$ National Association of Statutory Health Insurance Physicians of Bavaria, Munich, Germany, ${ }^{4}$ Institute of General Practice School of Medicine, Technical University of Munich, Munich, Germany, ${ }^{5}$ Munich Cluster for Systems Neurology (SyNergy), Munich, Germany
\end{abstract}

\section{OPEN ACCESS}

Edited by:

Jeannette Lechner-Scott, Hunter New England Health, Australia

Reviewed by: Katia Mattarozzi, Università degli Studi di Bologna, Italy

Merja Hannele Soilu-Hänninen,

University of Turku, Finland Carmen Lienert,

Kliniken Valens, Switzerland

*Correspondence:

Bernhard Hemmer hemmer@tum.de

tThese authors have contributed equally to this work

Specialty section: This article was submitted to

Neuroepidemiology,

a section of the journal

Frontiers in Neurology

Received: 22 July 2018 Accepted: 26 September 2018 Published: 30 October 2018

Citation:

Daltrozzo T, Hapfelmeier A, Donnachie E, Schneider A and Hemmer B (2018) A Systematic Assessment of Prevalence, Incidence and Regional Distribution of Multiple

Sclerosis in Bavaria From 2006 to

2015. Front. Neurol. 9:871

doi: 10.3389/fneur.2018.00871
Introduction: Worldwide, incidence and prevalence of multiple sclerosis (MS) have increased over the last decades. We present a systematic epidemiological study with recent prevalence and incidence rates of MS in Bavaria.

Methods: Incidence and prevalence of MS stratified by gender, age groups and region were analyzed by data records from 2006 to 2015 of more than 10 million people insured by the Bavarian Association of Statutory Health Insurance Physicians. Official statistics of the German Federal Ministry of Health provided the size of the general population. Future prevalence was estimated with a predictive model.

Results: From 2006 to 2015 prevalence of MS in Bavaria increased from 171 per 100,000 to 277 per 100,000, while incidence rates remained relatively stable (range 16-18 per 100,000 inhabitants with a female to male ratio between 2.4:1 and 2:1). Incidence and prevalence were higher in urban than urbanized and rural areas. The prevalence is expected to increase to 374 per 100,000 in 2040 with the highest prevalence rates between 50 and 65 years.

Conclusion: The prevalence of MS in Bavaria is among the highest worldwide and will further rise over the next two decades. This demonstrates a need to strengthen healthcare provision systems due to the increasing numbers of particularly older patients with MS in the future.

Keywords: multiple sclerosis, prevalence, incidence, regional distribution, Bavaria, Germany

\section{INTRODUCTION}

Multiple sclerosis (MS) is one of the leading causes for disability in young adults with a major impact on quality of life of the affected persons $(1,2)$. Europe is a region with high prevalence rates with half of the persons reported to be affected by MS in the world living in Europe $(3,4)$. Population-based data from 1985 to 2011 suggest an increase of prevalence of MS worldwide with an increase of the overall number of people with MS from 2.1 million in 2008 to 2.3 million in 2013 
according to the WHO (3-5). In population-based studies from 1985 to 2011, worldwide incidence rates of MS ranged from $<1$ per 100,000 to $>10$ per $100,000(4,6,7)$. The prevalence and incidence of MS is higher for women than men (ranging from 1.1:1 to $3: 1$ in the majority of European studies) (4). Over the last decades, prevalence and incidence grew at a faster rate in women than in men (4, 6-9).

In central Europe, including Switzerland, Germany, Austria and Hungary, prevalence rates ranged from 62 per 100,000 to 128 per 100,000 with the lowest rates found in the 1990s in Hungary and the highest prevalence rates analyzed in 2006 in Germany (4).

From 2005 to 2009 an increase of prevalence from 102 per 100,000 to 143 per 100,000 in Germany was reported (10). At the beginning of this century, the overall number of MS patients in Germany was estimated with approximately 120,000 to 140,000 patients and a female to male ratio of $2.5: 1(11,12)$. Recent estimations of the health care provision system report about an overall number of MS patients in Germany of 200,000 (13). Reported incidence rates ranged from 4.6 per 100,000 in 1985 to 8.0 per $100,000(14,15)$. Due to the variety of data sources and survey methods applied to different geographic populations, the comparability of such results is inherently limited.

This project aimed to estimate the prevalence and incidence of MS in the German federal state of Bavaria in the years of 2006-2015 together with their regional distribution. The study comprises a systematic retrospective analysis of anonymous claims data held by the Bavarian Association of Statutory Health Insurance Physicians, covering about $85 \%$ of the population of Bavaria.

\section{METHODS}

The incidence, prevalence and corresponding regional distribution of MS in Bavaria were estimated on a yearly basis from two different data sources. Ambulatory claims data held by the Bavarian Association of Statutory Health Insurance Physicians (BASHIP) were used to assess the number of MS patients with a secured ICD-10 diagnosis G35. Study data, aggregated by year gender and age group were extracted from a pseudonymised database created by the BASHIP for the purpose of health services research. Approval was obtained from the responsible data protection officer of the BASHIP. Data covered the years 2004 to 2016 and was stratified by region, gender and the age groups $[0,15),[15,20),[20,25), \ldots,[70,110]$. Here, the mathematical notation of intervals is used to indicate inclusion by squared brackets "[" and "]", and exclusion by round brackets "(" and ")". Therefore a patient transitions from the interval $[0,15)$ to the interval $[15,20)$ on the 15 th birthday, for example. Estimates of incidence and prevalence have also been standardized to the age distribution of the European standard population (ESP) and the WHO standard population to support comparability with data of other countries $(16,17)$.

A patient was considered to have MS if the secured ICD10 diagnosis G35 was present in at least two separate quarterly periods, not necessarily in the same year. The year of diagnosis was considered to be the year of incidence; a minimum period of 2.5 years was available by which to exclude a previous MS diagnosis. In subsequent years, the patient was only included in the prevalence count if a corresponding MS diagnosis was present. An MS diagnosis was assumed to be valid coded by a neurologist at least once during the observation period.

The underlying population was taken from the official KM 6statistic of the German Federal Ministry of Health. This details the number of statutorily insured persons in Bavaria by age group and gender, but not by administrative district. The latter was therefore inferred from the regional distribution of the patient's districts of residence as observed in the BASHIP claims data.

Patients were also aggregated according to the regional planning districts as defined by the German Federal Institute for Research on building, urban affairs and spatial development, each containing between 317,000 and 2.8 million residents and classified using the categories urban, partially urbanized and rural. In urban areas, $50 \%$ of the population live in cities and the overall population density is $>150$ inhabitants per $\mathrm{km}^{2}$. In rural areas, less than $50 \%$ of the population live in cities and the population density outside the cities is $<100$ inhabitants per $\mathrm{km}^{2}$. Intermediate regions are classed as partially urbanized.

Data were restricted to the years 2006 until 2015. In an additional analysis, the prevalence for the period 2020-2040 was forecast starting with the actual data for the year 2015. For each discrete 5-year interval, the count of MS patients and the size of the general population in 2015 were transitioned from one age group to the next. At each step, several factors including the MS incidence affect the group sizes either positively or negatively. The mean values of the age specific incidence rates, which proved to be rather stable within the years 2006-2015, were used for this computation. Assuming a uniform distribution of age within the age groups, each subject spends an average of 2.5 years under the risk of two subsequent age groups considering a time interval of 5 years. The corresponding incidence rates where therefore each multiplied by a factor of 2.5 and applied to the size of the general population of a given age group to add the resulting expected count of new MS diagnoses in the transition of this age group to the next age group for a step of 5 years. In the same manner and taking the same effect, one-third of the MS patients and the general population in age group $[0,15)$ transitioned to the next age group. The size of the age group $[0,15)$ was kept stable in this analysis, which assumes constant birth rates. This stable amount of subjects not transitioning into the next age group stayed under a stable risk estimated for this age group $[0,15)$ for five years in each step. There was also no transition of patients from the age group [70,110] to any older age group and subjects stayed under the risk of this age group, i.e., applying the corresponding incidence, for a period of 5 years in each step. Taking a negative effect on the count of MS patients, e.g., due to death, movements or any other cause, dropout rates were computed for each age group and year from the BASHIP claims data by identification of MS patients with terminating records, i.e., patients without any claims records of any kind in the years after a given year. These dropout rates were rather 
stable and were averaged across years for each age group and gender. In the transition of MS patients from one age group to the other, i.e., for a time shift of 5 years, the average dropout rate of two subsequent age groups was applied five times to resemble yearly dropout. Further losses and gains also had to be expected for any cause, such as death and population movement, in the general population. Annual dropout and accrual rates between 2013 and 2014 stratified by age group and gender were therefore estimated using the so-called "birth day sample" (German: Geburtstagsstichprobe) of anonymous claims data that has been augmented with a list of all insured persons and is available from the german Institut des Bewertungsausschusses (18). These rates were used to adjust the size of the general population in the forecast as described for the dropout of MS patients above. Concerning the oldest age group $[70,110]$ it is evident that dropout, most likely due to death, has to be taken into account as otherwise, this group size would constantly rise due to subjects transitioning into this age group with each step of 5 years taken in the forecast.

All computations were performed in R 3.4.2 (R Foundation for Statistical Computing, Vienna, Austria).

\section{RESULTS}

\section{General Aspects}

Of the 12.8 million inhabitants of Bavaria in 2015, approximately $83.5 \%$ were covered by statutory health insurance plans (Federal Statistical Office, 2015). Characteristics of the populations of statutorily and privately insured persons can be inferred from the 2015 microcensus results provided by the Federal Statistical Office. Therefore the median age of statutorily and privately insured persons was 46 and 48 years, with 52.3 and $41.5 \%$ women and a median net income of 900-1300€ and 2000-2600€, respectively. Gender is a well-known risk factor for MS and has been taken into account in the following computations.

\section{Prevalence}

The overall prevalence of MS in Bavaria increased by $62 \%$, from 171 per 100,000 in 2006 to 277 per 100,000 in 2015 (Figure 1A, Table 1). The prevalence standardized to the age distribution of the European standard population and the WHO standard population are also given in Figure 1A and Table 1. In 2015 , about 30,000 of 10,720,000 Bavarians enrolled in statutory

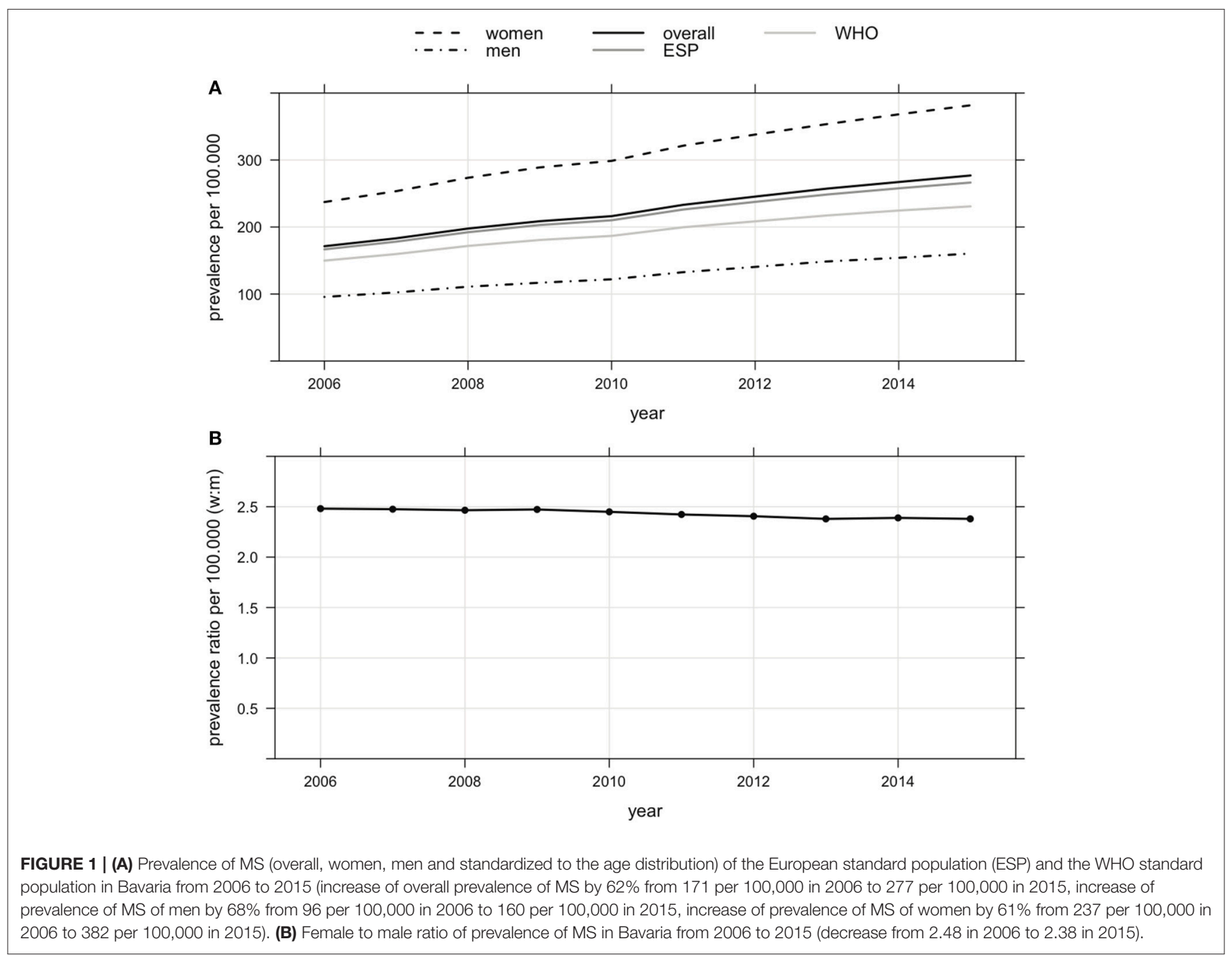


TABLE 1 | Overall Incidence and Prevalence of MS in Bavaria.

\begin{tabular}{|c|c|c|c|c|c|c|c|c|c|c|c|}
\hline & & 2006 & 2007 & 2008 & 2009 & 2010 & 2011 & 2012 & 2013 & 2014 & 2015 \\
\hline \multirow[t]{5}{*}{ Women } & MS Cases & 13,175 & 14,084 & 15,205 & 16,047 & 16,558 & 17,809 & 18,775 & 19,713 & 20,669 & 21,548 \\
\hline & New Cases & 1344 & 1,251 & 1,361 & 1,247 & 1,258 & 1,243 & 1,296 & 1,338 & 1,338 & 1,221 \\
\hline & Population & $5,552,393$ & $5,555,248$ & $5,559,404$ & $5,553,047$ & $5,542,847$ & $5,541,188$ & $5,554,480$ & $5,574,694$ & $5,613,912$ & $5,645,713$ \\
\hline & Prevalence & 237.29 & 253.53 & 273.5 & 288.98 & 298.73 & 321.39 & 338.02 & 353.62 & 368.17 & 381.67 \\
\hline & Incidence & 24.21 & 22.52 & 24.48 & 22.46 & 22.70 & 22.43 & 23.33 & 24.00 & 23.83 & 21.63 \\
\hline \multirow[t]{5}{*}{ Men } & MS cases & 4,624 & 4,957 & 5,387 & 5,673 & 5,919 & 6,452 & 6,885 & 7,341 & 7,724 & 8,138 \\
\hline & New cases & 499 & 445 & 536 & 480 & 512 & 524 & 539 & 582 & 548 & 543 \\
\hline & Population & $4,834,814$ & 4,840,349 & 4,855,989 & $4,854,931$ & 4,853,063 & $4,864,607$ & $4,900,891$ & $4,939,410$ & $5,012,757$ & $5,074,075$ \\
\hline & Prevalence & 95.64 & 102.41 & 110.94 & 116.85 & 121.96 & 132.63 & 140.48 & 148.62 & 154.09 & 160.38 \\
\hline & Incidence & 10.32 & 9.19 & 11.04 & 9.89 & 10.55 & 10.77 & 11.00 & 11.78 & 10.93 & 10.70 \\
\hline \multirow[t]{2}{*}{ Ratio (w:m) } & Prevalence & 2.48 & 2.48 & 2.47 & 2.47 & 2.45 & 2.42 & 2.41 & 2.38 & 2.39 & 2.38 \\
\hline & Incidence & 2.35 & 2.45 & 2.22 & 2.27 & 2.15 & 2.08 & 2.12 & 2.04 & 2.18 & 2.02 \\
\hline \multirow[t]{5}{*}{ Total } & MS Cases & 17,799 & 19,041 & 20,592 & 21,720 & 22,477 & 24,261 & 25,660 & 27,054 & 28,393 & 29,686 \\
\hline & New Cases & 1,843 & 1,696 & 1,897 & 1,727 & 1,770 & 1,767 & 1,835 & 1,920 & 1,886 & 1,764 \\
\hline & Population & 10,387,207 & $10,395,597$ & $10,415,393$ & $10,407,978$ & $10,395,910$ & $10,405,795$ & $10,455,371$ & $10,514,104$ & $10,626,669$ & $10,719,788$ \\
\hline & Prevalence & 171.36 & 183.16 & 197.71 & 208.69 & 216.21 & 233.15 & 245.42 & 257.31 & 267.19 & 276.93 \\
\hline & Incidence & 17.74 & 16.31 & 18.21 & 16.59 & 17.03 & 16.98 & 17.55 & 18.26 & 17.75 & 16.46 \\
\hline \multirow[t]{2}{*}{$\mathrm{ESP}^{\star}$} & Prevalence & 166.7 & 178.18 & 192.24 & 202.98 & 210.09 & 226.19 & 237.55 & 248.51 & 257.8 & 266.36 \\
\hline & Incidence & 17.14 & 15.85 & 17.66 & 16.19 & 16.67 & 16.56 & 17.2 & 17.91 & 17.38 & 15.98 \\
\hline \multirow[t]{2}{*}{$\mathrm{WHO}^{*}$} & Prevalence & 149.87 & 159.66 & 171.79 & 180.67 & 186.74 & 199.65 & 208.48 & 217.24 & 224.62 & 230.8 \\
\hline & Incidence & 17.81 & 16.58 & 18.44 & 17 & 17.59 & 17.31 & 18.06 & 18.67 & 18.33 & 16.88 \\
\hline
\end{tabular}

${ }^{\star}$ Estimates standardized to the age distribution of the European standard population (ESP) and the WHO standard population.

health insurance plans were diagnosed with MS. Assuming a similar prevalence across Germany, this would suggest that approximately 230,000 persons were diagnosed with MS in 2015. The prevalence in the male population increased by $68 \%$, from 96 per 100,000 in 2006 to 160 per 100,000 in 2015 (Figure 1A, Table 1). The prevalence in the female population increased by $61 \%$, from 237 per 100,000 in 2006 to 382 per 100,000 in 2015 (Figure 1A, Table 1). Thus, the female to male ratio remained largely unchanged during the observation period, equalling 2.48 in 2006 and 2.38 in 2015 (Figure 1B, Table 1).

The MS prevalence increased in all age groups (Figure 2A, Table 2). Overall, the median age was not different in 2006 and 2015, varying between 40 and 45 years. Therefore, 50\% of the MS patients were at least 40 years. In both men and women, the strongest increase in prevalence was observed in those aged 4060 years old. The median of the female to male ratios computed within the age groups showed only little change during the observation period, ranging from 2.49 in 2006 to 2.41 in 2015 (Figure 2B, Table 2). The female to male ratio was higher in young adults (Figure 2B, Table 2).

\section{Incidence}

The incidence of MS was investigated in the same population. Between 2006 and 2015 the incidence remained rather stable (median 17.3, range 16.3 to 18.3 per 100,000 inhabitants,
Table 1). The incidence standardized to the age distribution of the European standard population and the WHO standard population are also given in this Table 1. Incidence was higher among women (median 23.0, range 21.6-24.5 per 100,000) than among men (median 10.7, range $9.2-11.8$ per 100,000).

The highest incidence rates were found in persons aged 2050 years, with a peak incidence rate of 30.3 per 100,000 in men aged $30-35$ and 61.1 per 100,000 in women aged 25-30 (Table 2). Incidence rates increased slightly in the age group 15-30 but decreased slightly in older patients during the observation period.

\section{Regional Distribution}

The prevalence was higher in urban areas compared to partially urbanized and rural areas. In 2015, the prevalence was 293 in urban, 287 in partially urbanized and 262 per 100,000 in rural areas (Figure 3A). Between 2006 and 2015, the prevalence increased in urban areas by $54 \%$, in urbanized areas by $68 \%$ and in rural areas by $64 \%$. Incidence rates were higher in urban areas as compared to partially urbanized or rural areas (Figure 3B).

\section{FUTURE PREVALENCE RATES}

The future prevalence rates in Bavaria were estimated as outlined in the methods section. According to our predictive model, the prevalence is set to reach 353 per 100,000 inhabitants by 2030 

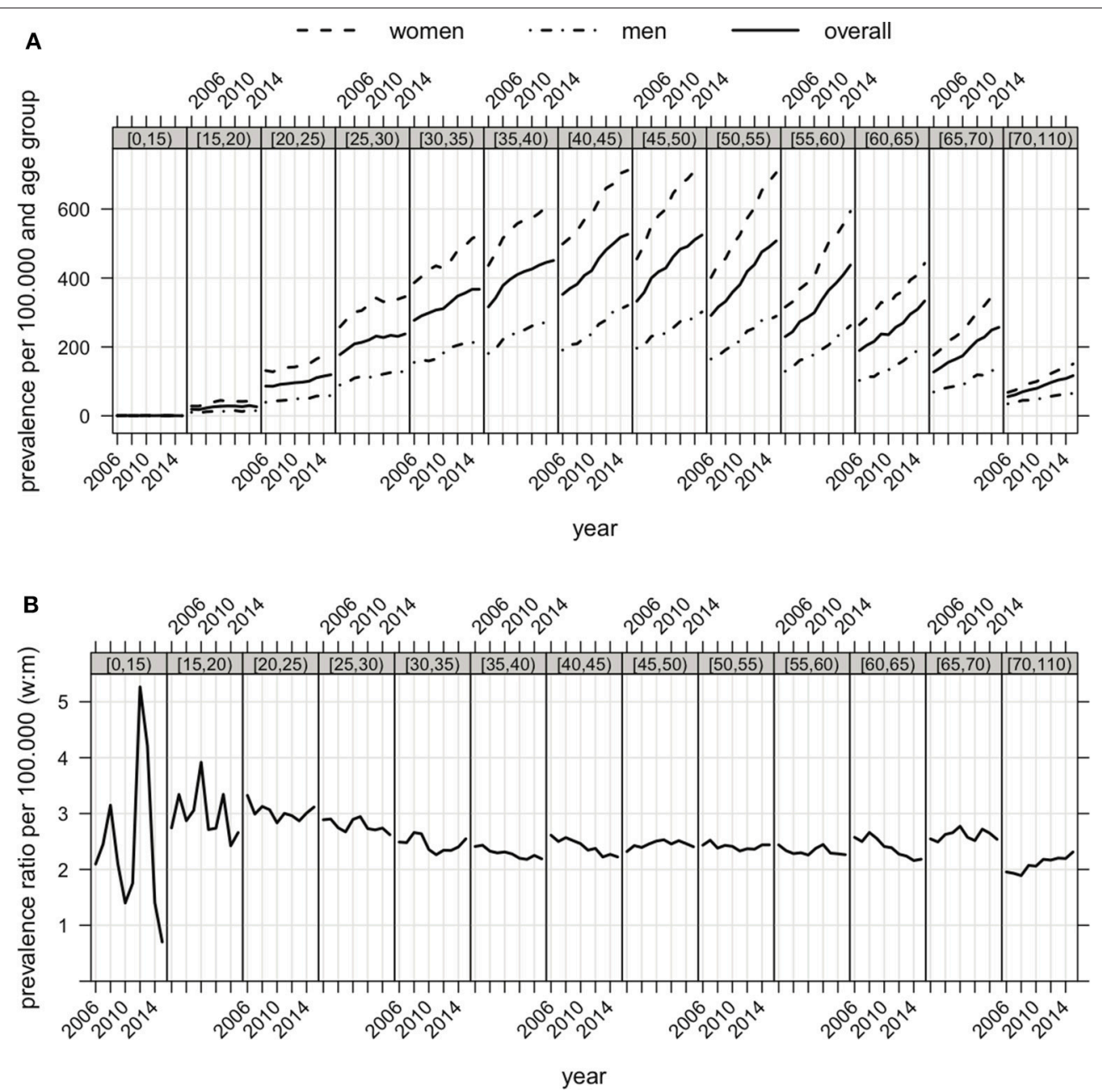

FIGURE 2 | (A) Prevalence of MS in Bavaria (overall, women and men) correspondent to age groups (displayed in the gray bar on top of each graph) from 2006 to 2015. (B) Female to male ratio of prevalence of MS in Bavaria correspondent to age groups from 2006 to 2015.

and 374 per 100,000 inhabitants by 2040 , with $50 \%$ of the MS patients being older than 45 years in 2040 (Figure 4A). While a small decrease in prevalence is expected in patients below the age of 45 , a sharp increase is expected among older people. In 2040 , the highest prevalence will be observed in the people aged between 50 and 65 years (Figure 4B).

\section{DISCUSSION}

Multiple sclerosis is one of the leading causes of disability in young adults. Besides individual implications for the affected people, the disease represents a significant socioeconomic burden to society. We present the first authoritative data on the prevalence and incidence of MS in Bavaria, one of the largest states in Germany with more than 12 million inhabitants. We observed a notable increase in the number of MS patients over the last decade, with 18,000 Bavarians enrolled in public health insurance plans being affected in 2006 and 30,000 in 2015. This corresponds to a $62 \%$ increase in the overall prevalence, reaching
277 MS patients per 100,000 Bavarians in 2015. Assuming the same prevalence in Germany as a whole, this would suggest that currently more than 230,000 Germans are diagnosed with MS. As the prevalence among women increased at the same rate as among men between 2006 and 2015, the female to male ratio remained largely unchanged. There was no trend in the incidence rates over the last decade, which ranged from 16 to 18 per 100,000 people. We observed a slightly higher prevalence and incidence of MS in urban areas as compared to partially urbanized and rural areas. According to our forecast, the prevalence of MS will further increase at least until 2040, when we predict a prevalence of almost 374 per 100,000 Bavarians, with more than $50 \%$ of MS patients being older than 45 years. Assuming a similar trend across Germany, this would translate into more than 300,000 Germans diagnosed with MS in 2040. A sharp increase of prevalence is expected for people aged between 55 and 70 years while a small decrease in prevalence is expected in patients below the age of 45 .

Previous studies of prevalence and incidence have applied different methodological approaches and can be affected 
TABLE 2 | Age dependent Incidence and Prevalence of MS in Bavaria.

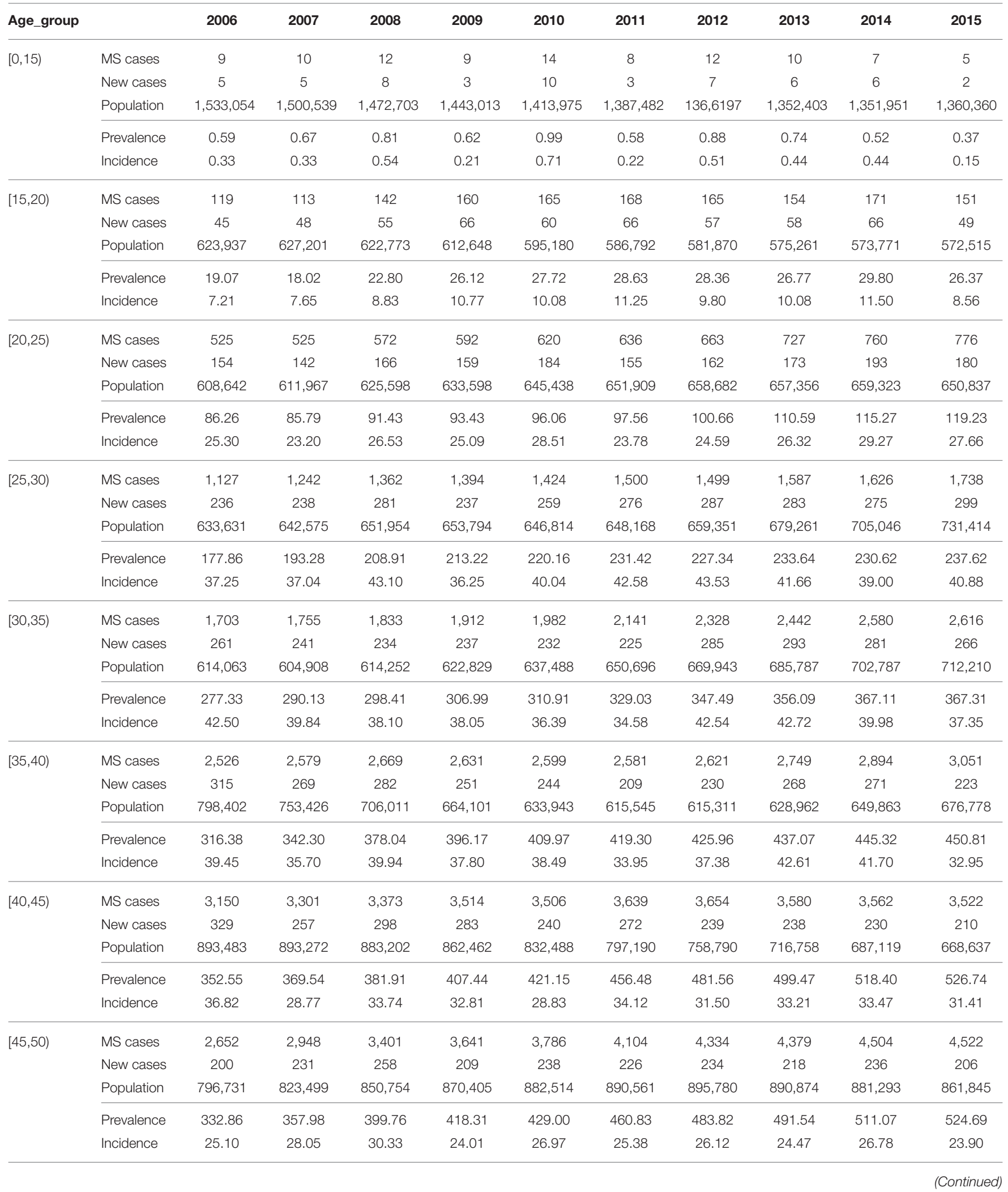


TABLE 2 | Continued

\begin{tabular}{|c|c|c|c|c|c|c|c|c|c|c|c|}
\hline age_group & & 2006 & 2007 & 2008 & 2009 & 2010 & 2011 & 2012 & 2013 & 2014 & 2015 \\
\hline \multirow[t]{5}{*}{50,55} & MS cases & 1,934 & 2,156 & 2,343 & 2,636 & 2,908 & 3,333 & 3,615 & 4,060 & 4,312 & 4,560 \\
\hline & New cases & 139 & 118 & 133 & 130 & 130 & 154 & 142 & 173 & 145 & 160 \\
\hline & Population & 663,667 & 681,315 & 705,433 & 732,961 & 763,466 & 794,711 & 823,634 & 853,777 & 880,535 & 898,352 \\
\hline & Prevalence & 291.41 & 316.45 & 332.14 & 359.64 & 380.89 & 419.40 & 438.91 & 475.53 & 489.70 & 507.60 \\
\hline & Incidence & 20.94 & 17.32 & 18.85 & 17.74 & 17.03 & 19.38 & 17.24 & 20.26 & 16.47 & 17.81 \\
\hline \multirow[t]{5}{*}{55,60} & MS cases & 1,423 & 1,532 & 1,728 & 1,813 & 1,916 & 2,190 & 2,453 & 2,687 & 2,986 & 3,339 \\
\hline & New cases & 59 & 70 & 89 & 63 & 90 & 85 & 93 & 96 & 84 & 84 \\
\hline & Population & 618,679 & 627,952 & 632,366 & 636,199 & 640,150 & 654,434 & 672,654 & 698,240 & 730,463 & 763,296 \\
\hline & Prevalence & 230.01 & 243.97 & 273.26 & 284.97 & 299.30 & 334.64 & 364.67 & 384.82 & 408.78 & 437.44 \\
\hline & Incidence & 9.54 & 11.15 & 14.07 & 9.90 & 14.06 & 12.99 & 13.83 & 13.75 & 11.50 & 11.00 \\
\hline \multirow[t]{5}{*}{60,65} & MS cases & 985 & 1,074 & 1,143 & 1,288 & 1,368 & 1,536 & 1,632 & 1,801 & 1,903 & 2,070 \\
\hline & New cases & 40 & 25 & 34 & 41 & 41 & 48 & 40 & 43 & 37 & 36 \\
\hline & Population & 519,345 & 524,174 & 529,933 & 542,222 & 580,978 & 597,700 & 606,367 & 610,917 & 616,057 & 621,266 \\
\hline & Prevalence & 189.66 & 204.89 & 215.69 & 237.54 & 235.47 & 256.99 & 269.14 & 294.80 & 308.90 & 333.19 \\
\hline & Incidence & 7.70 & 4.77 & 6.42 & 7.56 & 7.06 & 8.03 & 6.60 & 7.04 & 6.01 & 5.79 \\
\hline \multirow[t]{5}{*}{65,70} & MS cases & 858 & 920 & 972 & 961 & 909 & 965 & 1,077 & 1,142 & 1,274 & 1,406 \\
\hline & New cases & 34 & 27 & 35 & 25 & 15 & 17 & 28 & 28 & 28 & 28 \\
\hline & Population & 673,449 & 654,293 & 625,791 & 584,910 & 521,565 & 489,285 & 493,699 & 499,743 & 511,731 & 547,514 \\
\hline & Prevalence & 127.40 & 140.61 & 155.32 & 164.30 & 174.28 & 197.23 & 218.15 & 228.52 & 248.96 & 256.80 \\
\hline & Incidence & 5.05 & 4.13 & 5.59 & 4.27 & 2.88 & 3.47 & 5.67 & 5.60 & 5.47 & 5.11 \\
\hline \multirow[t]{5}{*}{70,100} & MS cases & 788 & 886 & 1,042 & 1,169 & 1,280 & 1,460 & 1,607 & 1,736 & 1,814 & 1,930 \\
\hline & New cases & 26 & 25 & 24 & 23 & 27 & 31 & 31 & 43 & 34 & 21 \\
\hline & Population & $1,410,124$ & $1,450,476$ & 1,494,623 & $1,548,836$ & $1,601,911$ & 1,641,322 & 165,3093 & $1,664,765$ & $1,676,730$ & $1,654,764$ \\
\hline & Prevalence & 55.88 & 61.08 & 69.72 & 75.48 & 79.90 & 88.95 & 97.21 & 104.28 & 108.19 & 116.63 \\
\hline & Incidence & 1.84 & 1.72 & 1.61 & 1.48 & 1.69 & 1.89 & 1.88 & 2.58 & 2.03 & 1.27 \\
\hline
\end{tabular}

by inaccuracy of diagnosis and data ascertainment with subsequently restricted comparability. A study by Hoer A and coworkers analyzed the prevalence of MS in Bavaria from 2005 to 2009 using the same ambulatory claims data combined with prescribing data (10). The study took a different approach to identifying MS patients, requiring either a single diagnosis from a neurologist or psychiatrist or the collection of MS-specific medication from a pharmacy (10). It found that MS prevalence increased from 0.123 to $0.175 \%$, which was then projected to 102,000 to 143,000 patients in the whole German population (10). However, patient identification was based solely on a health insurance number that was subject to change (e.g., marriage, change of status or change of insurance company). The use of a persistent patient identifier enables the present study to observe patients reliably over the entire observation period, improving estimation of prevalence and enabling the estimation of incidence.

Another study evaluated nationwide Statutory Health Insurance data covering both inpatient and outpatient services in Germany for the year 2010 counting approximately 200,000 patients with MS diagnosis (13). An investigation by Hein and coworkers used another approach with data based on representative samples of groups of physicians engaged in MS treatment, with the methodological risk of double counting and without the possibility of questioning the diagnosis (12).

In the present study we performed a systematic retrospective analysis of anonymous data held by the Bavarian Association of Statutory Health Insurance Physicians covering $83.5 \%$ of the Bavarian population between 2004 and 2016. In this respect the data of MS incidence, prevalence and regional distribution corresponded to a great majority of the Bavarian population. The data represent the claims of outpatient health care providers (outpatient clinics, general practitioners and registered medical specialists) and contains broad and objective information related to MS patients. The data include regional information, allowing stratification not only by age group and gender, but also by regional aspects. A minimum observation period of 2.5 years was used to rule out any prior MS diagnoses. We provide evidence to show that the prevalence in Bavaria is among the highest in the world, reaching 277 MS patients per 100,000 people in 2015.

Studies from other countries reported similar prevalence rates such as Canada (240 per 100,000 in 2000/2001), Northern Ireland 


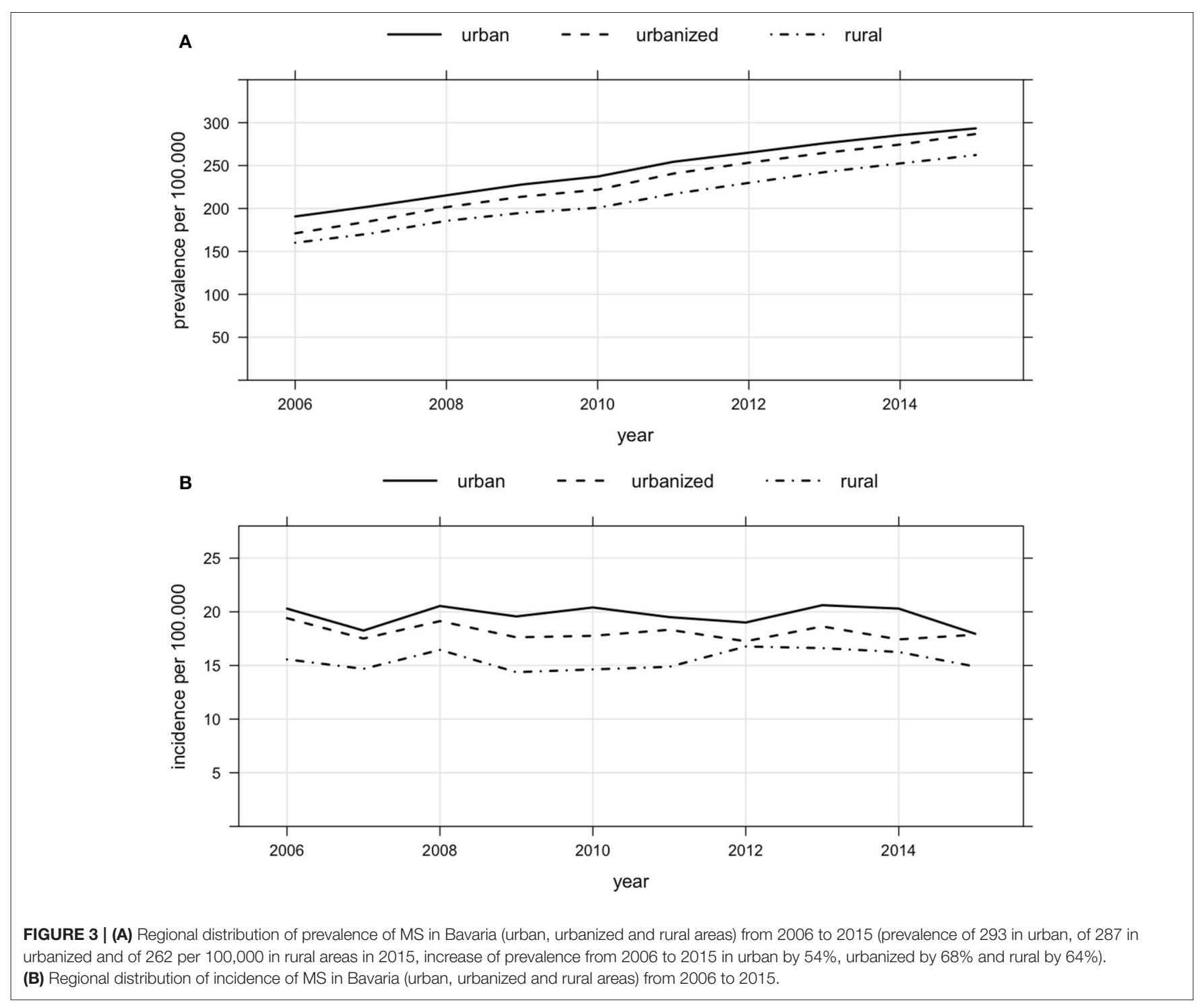

(200.5 per 100,000 in 1996) and Scotland (between 203 and 219 per 100,000) (19-21). Older studies from central European countries like Hungary (62-65 per 100,000 people at the end of the 1990s), Austria ( 98.5 per 100,000 at the end of the 1990s) and Switzerland (110 per 100,000 in 1986) reported lower prevalence rates (22-25). We observed an increased prevalence over the past decade similar to the results reported by studies from Denmark (58.8 in 1950 to 154.5 per 100,000 in 2005) and Norway (19.3 in 1980 to 182.4 per 100,000 in 2010$)(4,26,27)$.

Several investigations provide evidence for an increasing incidence of MS (e.g., in northern Finland with an increase especially in women from 1992 to 2007 and in the Nordland County of Norway from 0.7 per 100,000 in 1970 to 1974 to 10.1 per 100,000 in 2005 to 2009$)(27,28)$. In our study, we found that incidence rates were stable in Bavaria between 2006 and 2015. This is one of the surprising findings of our study with an increase in prevalence despite stable incidence rates during the observation period. This might be due to an increase in incidence before the observation period, possibly caused by the broad availability of magnetic resonance imaging and introduction of new diagnostic criteria in 1983 and $2001(29,30)$. The access to more and more effective immunotherapies may have improved life expectancy of affected patients and thus have increased MS prevalence despite stable incidence rates $(4,31)$.

Focusing on the female to male ratio of prevalence and incidence of MS, meta-analyses of studies over the previous 20-30 years provide evidence of a general but not ubiquitous increase in the female to male ratio of incidence of MS possibly due to changes in lifestyle, particularly among women $(8,32)$. In the present study, the prevalence increased at the same rate in the male and female populations between 2006 to 2015 .

Looking at the regional distribution, our study found that urban areas were associated with a higher prevalence than partially urbanized and rural areas. Moreover, incidence rates were higher in urban as compared to partially urbanized and rural areas. These results are in line with data of studies 

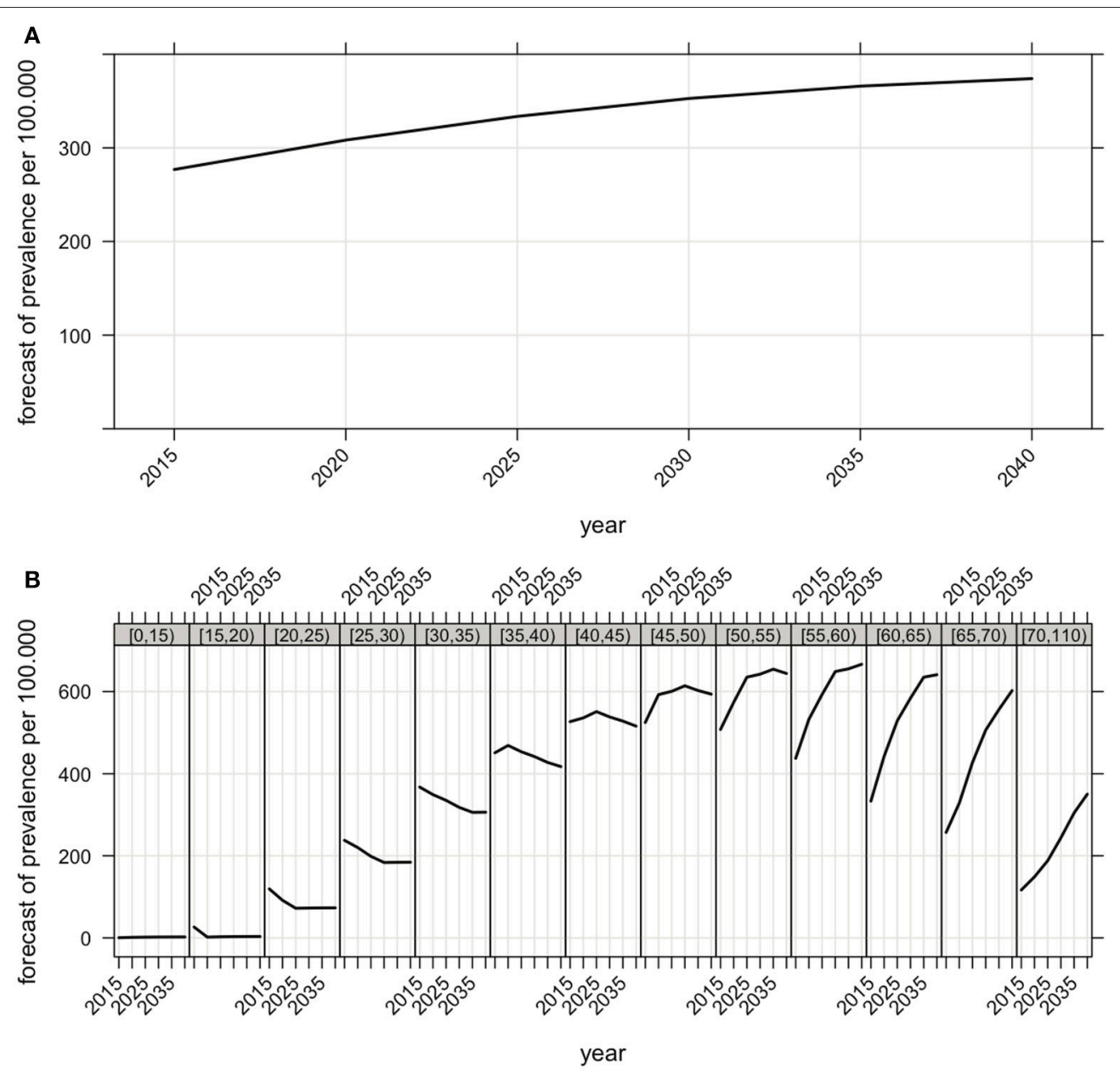

FIGURE 4 | (A) Forecast of the future overall prevalence of MS in Bavaria (the prevalence of 277 per 100,000 inhabitants in 2015 is expected to increase to 353 per 100,000 inhabitants by 2030 and to 374 per 100,000 inhabitants by 2040). (B) Forecast of the future prevalence of MS correspondent to age groups in Bavaria.

Computational details are given in the methods section.

of Finland, Canada and South America that show regional differences in MS prevalence and incidence (19, 32-34). These differences might be explained by a better access of patients to health care providers in urbanized and urban areas including neurological doctor's offices as well as radiologists with MRI scanners $(19,31-36)$. Also environmental factors might contribute to regional differences $(32-34,37)$.

In this study, data on ethnic differences in the development of MS prevalence and incidence rates in the last years was not available but would be of great interest for future studies.

Our study has certain limitations. The diagnosis of MS is based on the assessment of individual Bavarian neurologists in private practice. In this respect, the diagnostic MS criteria on which clinicians based their diagnosis are unknown. Because physicians in private practice are required to participate in continuing education training and many activities for neurologists are focused on MS, we assume a high standard of MS care in private practice including knowledge on the current diagnostic MS criteria.
Patients undiagnosed in the preliminary stages of the disease and otherwise unreported cases are unaccounted for, possible leading to an underestimation of the prevalence of MS in Bavaria. Another reason for an underestimation of prevalence could be incorrect coding by physicians. Most frequently, physicians used non-specified MS diagnosis codes (ICD-10 code G35.9), hence there is only partial information on the frequency of different types and courses of MS in Bavaria. The study data encompassed $83.5 \%$ of the total Bavarian population (see Methods), limiting generalizability to the population as a whole. Moreover, the data do not cover the treatment of patients in hospitals or in outpatient units of university hospitals. Furthermore another diversification of the study might be a possible difference of the Bavarian population compared to the overall German population in respect to demographic characteristics. We counteracted this fact by using age-group- and gender-specific measures for a projection of the results onto the entire German population and standardized our results to the age distribution of the European standard population (ESP) and the WHO standard population. 
However we cannot rule out further, unmeasured differences in the demographic and regional structure.

In summary, our results on population based insurance data depict a considerable increase of MS prevalence in Bavaria from 2006 to 2015. The rise of prevalence of MS demonstrates a need to strengthen healthcare provision systems due to the increasing numbers of particularly older patients with MS in the next years. Future research should extend these data to the entirety of Germany. Precise information about the distribution of MS in Germany is necessary to inform the capacity planning of health care services from an economic perspective as well as from the perspective of those affected by MS.

\section{ETHICS STATEMENT}

For this retrospective study anonymous claims data of people insured by the Association of Statutory Health Insurance Physicians of Bavaria from 2006 to 2015 were analyzed. Official statistics of the German Federal Ministry of Health were used to

\section{REFERENCES}

1. Compston A, Coles A. Multiple sclerosis. Lancet (2008) 372: 1502-17. doi: 10.1016/S0140-6736(08)61620-7

2. Thompson AJ, Baranzini SE, Geurts J, Hemmer B, Ciccarelli O. Multiple sclerosis. Lancet (2018) 391: 1622-36. doi: 10.1016/S0140-6736(18)30481-1

3. WHO. Atlas Multiple Sclerosis Resources in the World. Geneva: WHO Press (2008).

4. Kingwell E, Marriott JJ, Jetté N, Pringsheim T, Makhani N, Morrow SA, et al. Incidence and prevalence of multiple sclerosis in Europe: a systematic review. BMC Neurol. (2013) 13:128. doi: 10.1186/1471-2377-13-128

5. Msif. Atlas of MS 2013: Mapping Multiple Sclerosis Around the World. Bethesda: Multiple Sclerosis International Federation (2013).

6. Dean G, Elian M, de Bono AG, Asciak R, Vella N, Mifsud V, et al. Multiple sclerosis in Malta in 1999: an update.[see comment]. J Neurol Neurosurg Psychiatry (2002) 73:256-60. doi: 10.1136/jnnp.73.3.256

7. Nicoletti A, Lo Fermo S, Reggio E. A possible spatial and temporal cluster of multiple sclerosis in the town of Linguaglossa, Sicily. J Neurol. (2005) 252: 921-5. doi: 10.1007/s00415-005-0781-4

8. Alonso A, Hernán M, Herna M. Temporal trends in the incidence of multiple sclerosis. Neurology (2008) 71: 129-35. doi: 10.1212/01.wnl.0000316802.35974.34

9. Trojano M, Lucchese G, Graziano G, Taylor BV, Simpson S Jr, Lepore V, et al. Geographical variations in sex ratio trends over time in multiple sclerosis. PLoS ONE (2012) 7:e48078. doi: 10.1371/journal.pone.0048078

10. Höer A, Schiffhorst G, Zimmermann A, Fischaleck J, Gehrmann L, Ahrens H, et al. Multiple sclerosis in Germany: data analysis of administrative prevalence and healthcare delivery in the statutory health system. BMC Health Serv Res. (2014) 14:381. doi: 10.1186/1472-6963-14-381

11. Flachenecker P, Stuke K, Elias W, Freidel M, Haas J, PitschnauMichel D, et al. Multiple sclerosis registry in Germany: results of the extension phase 2005/2006. Deutsches Ärzteblatt Int. (2008) 105:113-9. doi: 10.3238/arztebl.2008.0113

12. Hein T, Hopfenmüller W. Hochrechnung der Zahl an multiple Sklerose erkrankten Patienten in Deutschland. Nervenarzt (2000) 71:288-94. doi: 10.1007/s001150050559

13. Petersen G, Wittmann V, Arndt D, Göpffarth D. Epidemiologie der Multiplen Sklerose in Deutschland. Der Nervenarzt (2014) 85: 990-8. doi: 10.1007/s00115-014-4097-4

14. Poser S, Stickel B, Krtsch U, Burckhardt D, Nordman B. Increasing incidence of multiple sclerosis in South Lower Saxony, Germany. Neuroepidemiology (1989) 8: 207-13. doi: 10.1159/000110184 provide the size of the general population. An ethic votum was therefore not needed.

\section{AUTHOR CONTRIBUTIONS}

All authors listed have made a substantial, direct and intellectual contribution to the work, and approved it for publication.

\section{FUNDING}

$\mathrm{BH}$ is supported by the Bundesminsterium für Bildung und Forschung (Kompetenznetz Multiple Sklerose KKNMS and DIFUTURE), the Deutsche Forschungsgemeinschaft DFG (TR 128), and the EU (MultipleMS project).

\section{ACKNOWLEDGMENTS}

This work is associated with the DIFUTURE (Data Integration for Future Medicine, BMBF 01ZZ1804[A-F]) consortium.

15. Fasbender P, Kölmel HW. Incidence of multiple sclerosis in the urban area of Erfurt, Thuringia, Germany. Neuroepidemiology (2008) 30:147-51. doi: 10.1159/000122331

16. Pace M, Lanzieri G, Glickman M, Zupanič T. Revision of the European Standard Population: report of Eurostat's task force. Luxembourg: Publications Office of the European Union (2013).

17. Ahmad OB, Boschi-Pinto C, Lopez AD, Murray CLJ, Lozano R, Inoue M, et al. Age Standardization of Rates: A New WHO Standard. Geneva: World Health Organization (2001).

18. Institut des Bewertungsausschusses. Beschlusses des Bewertungsausschusses in seiner 308. Sitzung - Datensatzbeschreibung zur Datenübermittlung der nach Berlin: Wohnortprinzip aufbereiteten Geburtstagsstichprobe. Available online at: http://institut-ba.de (2013).

19. Beck CA, Metz LM, Svenson LW, Patten SB. Regional variation of multiple sclerosis prevalence in Canada. Multiple Scler. (2005) 11: 516-9. doi: 10.1191/1352458505ms1192oa

20. Gray OM, McDonnell GV, Hawkins SA. Factors in the rising prevalence of multiple sclerosis in the north-east of Ireland. Multiple Scler. (2008) 14:880-6. doi: 10.1177/1352458508090663

21. Rothwell PM, Charlton D. High incidence and prevalence of multiple sclerosis in south east Scotland: evidence of a genetic predisposition. J Neurol Neurosurg Psychiatry (1998) 64:730-5. doi: 10.1136/jnnp.64.6.730

22. Bencsik K, Radja C, Klivenyi $P$, Járdánházy $T$, Vécsei L. The prevalence of multiple sclerosis in the Hungarian city of Szeged. Acta Neurol Scand. (1998) 97: 315-9. doi: 10.1111/j.1600-0404.1998. tb05959.x

23. Bencsik K, Radja C, Füvesi J, Klivényi P, Járdánházy T, Török M, Vécsei L. The prevalence of multiple sclerosis, distribution of clinical forms of the disease and functional status of patients in Csongrád County, Hungary. Eur Neurol. (2001) 46: 206-9. doi: 10.1159/000050806

24. Baumhackl U, Eibl G, Ganzinger U, Hartung HP, Mamoli B, Pfeiffer KP, et al. Prevalence of multiple sclerosis in Austria. Results of a nationwide survey. Neuroepidemiology (2002) 21: 226-34. doi: 10.1159/000065640

25. Beer S, Kesselring J. High prevalence of multiple sclerosis in Switzerland. Neuroepidemiology (1994) 13:14-8. doi: 10.1159/000110353

26. Bentzen J, Flachs EM, Stenager E, Brønnum-Hansen H, Koch-Henriksen N. Prevalence of multiple sclerosis in Denmark 1950-2005. Multiple Scler. (2010) 16: 520-5. doi: 10.1177/1352458510364197

27. Benjaminsen E, Olavsen J, Karlberg M, Alstadhaug KB. Multiple sclerosis in the far north - incidence and prevalence in Nordland County, Norway, 1970-2010. BMC Neurol. (2014) 14:226. doi: 10.1186/s12883-0140226-8 
28. Krokki O, Bloigu R, Reunanen M, Remes AM. Increasing incidence of multiple sclerosis in women in Northern Finland. Multiple Scler. (2011) 17: 133-8. doi: 10.1177/1352458510384012

29. Poser CM, Paty DW, Scheinberg L, McDonald WI, Davis FA, Ebers GC, et al. New diagnostic criteria for multiple sclerosis: guidelines for research protocols. Ann Neurol. (1983) 13: 227-31. doi: 10.1002/ana.4101 30302

30. McDonald WI, Compston A, Edan G, Goodkin D, Hartung HP, Lublin FD, et al. Recommended diagnostic criteria for multiple sclerosis: guidelines from the international panel on the diagnosis of multiple sclerosis. Ann Neurol. (2001) 50:121-7. doi: 10.1002/ana.1032

31. Comi G, Radaelli M, Soelberg Sørensen P. Evolving concepts in the treatment of relapsing multiple sclerosis. Lancet (2017) 389: 1347-56. doi: 10.1016/S0140-6736(16)32388-1

32. Koch-Henriksen N, Sørensen PS. The changing demographic pattern of multiple sclerosis epidemiology. Lancet Neurol. (2010) 9:520-32. doi: 10.1016/S1474-4422(10)70064-8

33. Melcon MO. MS prevalence in Latin America. Multiple Scler. (2012) 18:1813-4.

34. Sumelahti ML, Tienari P, Hakama M, Wikström J. Multiple sclerosis in Finland: incidence trends and differences in relapsing remitting and primary progressive disease courses. J Neurol Neurosurg Psychiatry (2003) 74: 25-8. doi: $10.1136 /$ jnnp.74.1.25

35. Selchen D, Bhan V, Blevins G, Devonshire V, Duquette P, Grand'Maison F, et al. MS, MRI, and the 2010 McDonald criteria: a Canadian expert commentary. Neurology (2012) 79(23 Suppl. 2):1-15. doi: 10.1212/WNL.0b013e318 $277 \mathrm{~d} 144$

36. Lovblad KO, Anzalone N, Dörfler A, Essig M, Hurwitz B, Kappos L, Lee SK, Filippi M. MR imaging in multiple sclerosis: review and recommendations for current practice. Am J Neuroradiol. (2010) 31: 983-9. doi: 10.3174/ajnr. A1906

37. Sumelahti ML, Tienari PJ, Wikström J, Palo J, Hakama M. Regional and temporal variation in the incidence of multiple sclerosis in Finland 1979-1993. Neuroepidemiology (2000) 19: 67-75. doi: 10.1159/000026241

Conflict of Interest Statement: BH has served on scientific advisory boards for F. Hoffmann-La Roche Ltd., Novartis, Bayer AG, and Genentech; he has served as DMSC member for AllergyCare and TG therapeutics; he or his institution have received speaker honoraria from Biogen Idec, Teva Neuroscience, Merck Serono, Medimmune, Novartis, Desitin, and F. Hoffmann-La Roche Ltd.; his institution has received research support from Chugai Pharmaceuticals and Biogen; holds part of two patents; one for the detection of antibodies against KIR4.1 in a subpopulation of MS patients and one for genetic determinants of neutralizing antibodies to interferon $\beta$. AH: Received a honorarium from Biogen for consulting services for the Biogen Symposium on Statistical Methods in Real World Evidence 2017.

The remaining authors declare that the research was conducted in the absence of any commercial or financial relationships that could be construed as a potential conflict of interest.

Copyright (C) 2018 Daltrozzo, Hapfelmeier, Donnachie, Schneider and Hemmer. This is an open-access article distributed under the terms of the Creative Commons Attribution License (CC BY). The use, distribution or reproduction in other forums is permitted, provided the original author(s) and the copyright owner(s) are credited and that the original publication in this journal is cited, in accordance with accepted academic practice. No use, distribution or reproduction is permitted which does not comply with these terms. 